\title{
APRESENTAÇÃO
}

\section{As imagens no tempo e os tempos da imagem}

A onipresença da imagem na sociedade contemporânea, veiculada em distintos suportes tecnológicos e com múltiplas finalidades, tem estimulado o debate entre os estudiosos de diferentes áreas do conhecimento. Até há pouco tempo a imagem encontrava-se, praticamente, restrita ao domínio da disciplina de História da Arte e dos aportes da Estética, aos seus estudos formais e estilísticos. Na atualidade, a imagem tem propiciado a constituição de novos campos de pesquisa, atrelados à Antropologia, à Comunicação e aos novos paradigmas científicos. A História da Arte enfrenta um processo de revisão de conceitos, teorias e métodos norteadores e tem sido desafiada a repensar os processos de instauração das imagens, suas montagens e desmontagens, suas memórias e temporalidades, além de seus processos de exibição, circulação e legitimação.

A História também passa por mudanças ao valorizar e depositar maior confiança nas potencialidades da imagem como fonte de estudo do passado, mas consciente de que não basta perguntar somente que história ela documenta e de que história ela é contemporânea, mas que "memória ela sedimenta", ${ }^{1}$ que temporalidades ela evidencia.

Os estudos de imagens cristãs medievais ${ }^{2}$ colaboraram para o melhor entendimento histórico e antropológico. Nesses foi observada a sua eficácia espiritual e política para a formação do imaginário individual e coletivo, exercida pelos rituais, bem como outros usos e funções. Esses estudos possibilitaram ainda verificar o imago, como fundamento de uma Antropologia Cristã, que rejeitou a imitação da imagem antiga pagã para pro-

1 DIDI-HUBERMAN, Georges. La condition des images. Entretien avec Frédéric Lambert et François Niney. In: LAMBERT, F. L'éxpérience des images. Paris: INA Éditions, p. 95.

2 BELTING, Hans. Das Bild und Publikum im Mittelater. Berlim: Gebr. Mann Verlag, 1981. L'image et son public au moyen-âge. Paris: Gerard Monfort, 1998. Bild und Kult. Munique: Verlag C. H. Beck o H.G., 2004. Semelhança e presença. A história da imagem antes da era da arte. Rio de Janeiro: ARS URBE, 2010. SCHMITT, Jean-Claude. Le corps des images. Essais sur la culture visuelle au Moyen-Âge. Paris: Gallimard, 2002. O corpo das imagens. Ensaios sobre a cultura visual na Idade Média. Bauru, São Paulo, 2007. 
mover a transcendência. As cores e as formas se constituíram como indícios simbólicos de uma realidade invisível e da Encarnação. Ao mesmo tempo em que a imagem exercia eficácia espiritual e controle social, ela poderia simbolizar a posse de territórios, como o Vaticano, representar cidades, criar locais de peregrinação, dentre outras funções. Os historiadores puderam observar o poder da imagem e a presença de memórias e temporalidades distintas, de fantasmas, apesar da aversão cristã ao antigo mundo pagão.

Estudos recentes evidenciam que diante da imagem os tempos coexistem e revelam a sua complexidade, seus diferentes estratos se cruzam e se contradizem. Algumas imagens, como, por exemplo, as do fotojornalismo, revelam as memórias das tragédias e de acontecimentos de muçulmanos com reminiscências da iconografia cristã. $\mathrm{O}$ algeriano Hocine Zaourar apresenta na "Madona de Benthala" (1997) múltiplas memórias, desde as Pietás medievais, do Renascimento e, sobretudo, barrocas da religião cristã para manifestar o sofrimento da mulher no massacre de Benthala. Essas imagens, como outras, são montagens de diferentes memórias, estratos de tempos e lugares que se realizam pela via da contradição e que geram outras imagens em distintos suportes. ${ }^{3}$ As migrações simbólicas e as sobrevivências culturais, na longa duração, e em imagens de diferentes suportes técnicos, foram verificadas, no início do século XX, nos estudos de Aby Warburg relativos ao Renascimento florentino. ${ }^{4}$

Cinema, fotografia, publicidade, artes revelam as sobrevivências, os anacronismos e os reencontros de temporalidades contraditórias e descontínuas que compõem as imagens nas suas montagens, ao apresentarem a tessitura de resíduos, traços e vestígios de tempos distintos, de nossa memória inconsciente. $\mathrm{O}$ tempo não significa necessariamente o passado, mas a memória, porque ela decanta o passado, o humaniza e configura o tempo. A memória é psíquica no seu processo e é anacrônica nos seus efeitos de montagem, pois ela conecta o inconsciente. ${ }^{5}$

3 DIDI-HUBERMAN, Georges. Image, événement, durée. In: CARERI, Giovanni et al. Paris: Éditions de EHESS, 2009. Nesse texto, o autor apresenta a obra do artista contemporâneo Pascal Convert (1999-2004) efetuada a partir da fotografia de Georges Merillon (1990) sobre a previsão de catástrofe em Kosovo. O autor analisa o movimento das imagens sob outros suportes e diferentes temporalidades, além de salientar que o fotojornalismo provoca reflexões no público, a respeito das tragédias, e aciona novo olhar no artista.

4 WARBURG, A. A renovação da antiguidade pagã. Contribuições científico-culturais para a história do Renascimento europeu. Rio de Janeiro: Contraponto, 2013.

5 DIDI- HUBERMAN, Georges. Devant le temps. Paris: Éditions Minuit, 2000. p. 83-95. 
O dossiê ora apresentado aborda as relações entre a história e a imagem a partir desse recorte que privilegia o tempo humanizado e configurado em memória, ou seja, edificado pelo processo da montagem que resulta em narrativas audiovisuais, coleções de fotografias, ações performáticas, charges, exposições e obras de arte.

Ao mesmo tempo, vale lembrar que a noção de imagem contém um duplo âmbito, ou seja, a reminiscência (mental e mnemônica) e o produto físico (gravura, pintura, fotografia). ${ }^{6}$ Assim, toda a imagem também pode ser pensada enquanto um produto posto em circulação na sociedade, elaborado a partir de encargos e diretrizes ${ }^{7}$ concernentes à sua época de produção, comercializado, colecionado, exibido, consumido e ressignificado por um determinado público. As imagens impregnam sentidos e valores que se constroem justamente nessa dinâmica social, em que toda a produção e o consumo estético estão profundamente imbricados às formas de relacionamento social e político que se estabelecem nos mais variados contextos culturais. Tanto os produtos visuais que tensionam os nossos esquemas de interpretação da realidade e os nossos padrões de gosto quanto os que os reforçam fazem parte do nosso modo de dar sentido ao mundo em que vivemos. Apresentam particularidades próprias e conformam campos estritos de estudo (as artes visuais, o cinema, o design, a publicidade), mas, ao mesmo tempo, se articulam sutilmente a outros âmbitos da cultura, assumindo importante participação tanto nas "permanências" quanto nas "rupturas" que se processam na sociedade ao longo do tempo.

Desse modo, ao reunir pesquisadores cujos estudos recentes se debruçam sobre a questão das imagens no tempo e dos tempos da imagem em suas mais variadas significações, pretendemos, com este dossiê, explorar a diversidade de enfoques, além de fomentar o debate acerca da relevância e da complexidade dos estudos atuais acerca do tema. Os artigos ora apresentados enfocam, por ângulos variados, algumas questões relevantes sobre

6 Hans Belting diferencia tais âmbitos usando os termos em inglês image e picture. Ver: BELTING, Hans. Por uma antropologia da imagem. Concinnitas, n. 8, p. 66, jul. 2005.

7 Os conceitos de encargos e diretrizes são extraídos de Michael Baxandall e referem-se a: 1) encargos: a encomenda, a motivação para a edificação de um determinado artefato visual; 2) diretrizes: as diversas condições (estéticas, sociais, tecnológicas, ideológicas) envolvidas na realização do produto e que interferem nas suas finalidades e também na sua forma final. Ver: BAXANDALL, Michael. Padrões de intenção: a explicação histórica dos quadros. São Paulo: Companhia das Letras, 2006. 
memórias, temporalidade e circulação social das imagens que podem ser descritas, grosso modo, a partir de quatro eixos.

O primeiro diz respeito à abordagem dos arquivos e museus como espaço de acondicionamento de artefatos visuais (fotografias, impressos, móveis entalhados, obras de arte e seus registros documentais). Diz Raul Antelo, em seu artigo, que no museu reside "o espectro de uma destinação", descrevendo-o como "câmara de reclusão e confinamento da imagem". Tais espaços de reclusão são tomados como ponto de partida pelos autores dos artigos para pensar a dimensão temporal dos mesmos - desde a preservação e o "congelamento" da história, passando pelas ideias de imobilização do tempo, até a construção de memórias e a ressignificação de esquemas iconográficos que se repetem ao longo dos séculos. Este eixo perpassa os textos de Angela Brandão, Solange Lima e Vicente Sánchez-Biosca, que se debruçam sobre arquivos bem específicos, mas também o de Artur Freitas, que focaliza um caso de obra artística efêmera e de caráter notadamente anti-institucional, mas realizado dentro do espaço oficial de um museu.

O segundo eixo tangencia o suposto caráter "documental" da imagem técnica (fotografia e cinema) e sua capacidade de "capturar" o instante, um fragmento do tempo, cristalizando-o em imagens, fazendo-nos ver nelas elementos que muitas vezes nos escapam ao olho nu e construindo sentidos sociais. Ao mesmo tempo, essas imagens transformam-se, como diz Sánchez-Biosca, em "fantasmas de outros tempos que nos observam". $\mathrm{O}$ artigo de Josep Català também pontua essa "função maravilhosa e surpreendente que permite congelar o presente e convertê-lo, imediatamente, em memória visual" - fato que deslumbrou uma fase da modernidade que se empenhava em "converter o mundo num acúmulo de fatos pesáveis e mensuráveis, portanto, arquiváveis". Mas também outros sentidos menos ligados à vontade classificatória do mundo se constroem em torno dessa função de "congelamento do tempo" atribuída às fotografias. Apontando para uma prática social e cotidiana das fotografias de família, Solange Lima diz, em seu artigo, que as práticas de colecionismo de álbuns fotográficos podem ser entendidas enquanto "performances de caráter afetivo e emocional a serviço da rememoração". Artur Freitas tem como objeto de estudo um vídeo que é o único registro de uma obra "efêmera" que, sem tal registro, já não seria visualizável. E Ana Maria Mauad aponta para o âmbito social da circulação de fotografias documentais na mídia e a construção de sentidos 
em torno das mesmas, avaliando a dimensão temporal da fotografia enquanto uma "experiência vivencial".

Um terceiro eixo que perpassa os artigos deste dossiê diz respeito à montagem das imagens e suas memórias ou tempos diferentes, que se articulam à circulação de símbolos e suas sobrevivências na longa duração. No artigo de Sánchez-Biosca, isso se faz ver pela descrição dos usos das mesmas imagens filmográficas em variados contextos e narrativas. Ignácio Del Valle Dávila, por sua vez, analisa dois filmes históricos em que "passado e presente se inter-relacionam num jogo de espelhos". E, nas reflexões desenvolvidas por Català, ele menciona os espaços "metatemporais" que agrupam as distintas temporalidades das imagens que eles mesmos contêm, ou seja, que consistem em espécies de painéis, no sentido warburgiano, permitindo visualizar um "fluxo temporal que une as imagens de diferentes épocas". Essa dimensão, no que se refere à sobrevivência das imagens em tempos diferentes, é observável também nos textos de Ana Maria Mauad e de Angela Brandão, quando as duas autoras buscam enfatizar certos "diagramas", schemas ou matrizes iconográficas que são desenvolvidos culturalmente e que podem ser reconhecidos em imagens de contextos temporais bem distintos. Enfim, como escreveu Raul Antelo no início de seu artigo, "a história é montagem de temporalidades diversas" que obedecem à ilusão do "já-vivido".

E ainda um quarto eixo perceptível nos artigos é o enfoque sobre os diferentes usos históricos (temporais, portanto) das imagens, com finalidades políticas, cívicas ou didáticas. Esse eixo pode ser exemplificado tanto pela construção das imagens de personagens políticos quanto pelas missões cívicas, políticas e didáticas atribuídas ao cinema e às artes em certas políticas culturais, questões claramente apontadas nos artigos por Ignácio Del Valle Dávila, Eduardo Morettin e Rodrigo Tavares. Entretanto, outra forma de uso político da imagem - ou de ações visuais - pode ter como finalidade a provocação e a contestação em relação aos valores estéticos e políticos vigentes, como o caso tratado no artigo de Artur Freitas, que aponta para o caráter efêmero e impalpável de certas obras como forma de reação ao anseio pela "permanência".

Tais eixos, é importante frisar, não estão presentes com exclusividade em um ou outro texto. Estão, por assim dizer, mesclados e respingados nos diversos ângulos e objetos escolhidos pelos autores para elaboração de 
seus artigos. Vale, portanto, situar brevemente o leitor quanto ao conteúdo dos artigos que compõem este dossiê.

No texto de abertura, Josep M. Català Domènech mobiliza o conceito de "espaço-tempo" e apresenta-o como um dispositivo hermenêutico para se pensar a realidade, especialmente quando associado ao fenômeno cinematográfico e seus desdobramentos. Afirma que o pensamento histórico ainda não se adaptou às novas formas de pensar o tempo advindas com a invenção do cinema e com as teorias físicas desenvolvidas por Einstein e Minkowski (autor do conceito de espaço-tempo). Afirma que a história se ocupa muito pouco dos problemas do tempo, ainda que o considere a sua matéria-prima. Segundo Català, atualmente é preciso considerar uma nova dimensão do tempo recentemente detectada, que corresponde à fase em que o tempo está "sendo visualizado". Portanto, para compreender as dimensões deste fenômeno, se faz necessário buscar entender quais relações o tempo estabelece com a visualidade. Sua questão, no artigo, é refletir sobre o tipo de história que surge do "tempo visualizado", ou seja, do que se entende por tempo na era das imagens. Desde meados do século XIX vivemos um regime das "imagens instáveis", que aparecem na caricatura, na fotografia e até na literatura, e Català se pergunta se temos compreendido o que essa nova formação das imagens significa na história da representação visual. Para ele, o movimento aparece como a essência do tempo, já que se mostra como fator de transformação da percepção (e não como representação naturalista que supre uma carência da imagem fixa). Assim, o espaço-tempo visualizado, seja através do cinema ou das novas imagens de interface, se converte em nova ferramenta mental.

Em seguida, o artigo de Raul Antelo traz uma reflexão sobre os textos publicados pelo poeta e fotógrafo Sylvio da Cunha na coluna "Letras e Artes" do jornal carioca A Manhã ao longo de 1947 e 1948. Segundo Antelo, Sylvio Cunha teria elaborado "a primeira teoria da fotografia no Brasil", ou, talvez mais do que isso, uma "antropologia do sensível", por meio das ideias que se aproximam às de Walter Benjamin. Ao definir poesia, Cunha fala de "fotografias da memória" ou "imagens do pensamento". Ao falar sobre as origens da fotografia e as resistências a ela no século XIX, o poeta fala das sombras e das superstições em torno da "imagem refletida" e dos fantasmas (imagens-eidolom) que atravessam os séculos. "Os fotógrafos de 1850 eram manipuladores de sombras", dizia. E buscava definir uma estética para essa linguagem, identificando, entre os seus atributos, o 
aparecimento da quarta dimensão - o tempo - "no momento transitório e cambiante, uma face da eternidade que é possível contemplar livremente". Ao definir o cinema, Cunha o descrevia como "uma fotografia em estado de sonho". Observa-se, assim, uma articulação entre os dois textos - espaço-tempo de Català / fotografia como essa linguagem que contém o "tempo" como um de seus atributos.

Na sequência, o artigo de Vicente Sánchez-Biosca pode ser encarado como um estudo pontual sobre um conjunto de imagens que traduzem essa ideia de "tempo visualizado" ou, noutras palavras, permitem que fragmentos de um tempo passado sejam vistos por nós como verdadeiros fantasmas de um pesadelo histórico: as filmagens feitas no Gueto de Varsóvia ao longo dos meses de abril e junho de 1942, pouco antes das deportações dos judeus daquele Gueto para os campos de extermínio. Trata-se de um material que traz em si as marcas das condições do tempo e do lugar em que foi gestado e que se desvia, hoje, de sua possível função propagandística original (uma vez que foi produzido por cinematografistas a serviço do governo alemão), tornando-se ambíguo e, portanto, mais rico enquanto arquivo visual. Sánchez-Biosca se propõe a analisar usos documentais desse material de arquivo bruto ao longo do tempo: os modos como foi montado, sonorizado, trucado, explorado, pontuando que essas intervenções revelam aspectos das tendências hegemônicas de cada período histórico, tanto no âmbito estético quanto no ideológico. Aborda as estratégias de reapropriação deste material e de seus diferentes usos que fazem significar coisas distintas. Desse modo, o autor discute os processos de montagem da imagem e suas memórias ou tempos diferentes, apontando para sua sobrevivência na longa duração.

$\mathrm{O}$ artigo de Ana Maria Mauad também contém essa ideia de montagem e da sobrevivência da imagem em tempos diferentes, bem como discute a questão biográfica das imagens e seus significados culturais. Para tanto, toma como ponto de partida uma fotografia produzida pelo francês Marc Riboud, em 1967, que mostra uma moça com uma flor diante de soldados armados. Defende que a fotografia é "espécie de condensação de tempos que já não existem, mas permanecem estáticos na superfície fotográfica, como se previssem o futuro". Mobiliza o conceito de foto-ícone, associando-o ao estudo da cultura pública na democracia americana moderna, para então propor outra perspectiva para se operar com esse conceito, apoiando-se na noção de que todas as imagens possuem uma biografia, e de que "não existe uma história por detrás das imagens, mas imagens que 
fazem história". Para refletir sobre a fotografia de Riboud, toma como eixo a presença da flor como signo de paz, remontando à presença da flor nas representações da Anunciação na renascença italiana e projetando suas significações às imagens das movimentações de rua no Brasil de 2013. Aponta para essa trajetória de imagens no tempo para afirmar, pautada em Hans Belting, que "as imagens ganham corpo por meio de práticas sociais, em que sujeitos incorporam as imagens tanto como ideia e representação quanto como objetos, marcas corporais e gestos".

$\mathrm{O}$ artigo de Angela Brandão dá sequência ao dossiê e tem como ponto de partida um objeto pertencente ao Museu Arquidiocesano de Arte Sacra de Mariana, qual seja, um trono episcopal atribuído a Antônio Francisco Lisboa (datado de aproximadamente 1790), entalhado com um esquema decorativo composto por três figuras angelicais. A partir deste objeto, a autora estabelece uma reflexão em que busca identificar as "matrizes visuais destes elementos simbólico-decorativos: os querubins e os anjos portadores de mensagens". Ao articular a presença das figuras entalhadas no referido trono com uma narrativa que envolve a descrição de crianças, meninos seminus, anjos e Cupidos como personagens dos cortejos realizados para a chegada do primeiro bispo de Mariana, em 1748, Brandão propõe uma interpretação sobre a transposição das figuras aladas da arte Antiga - especialmente de Eros, por meio do neoplatonismo - para o Renascimento, transposição herdada pela arte barroca e rococó, num processo que "passava pelo deslocamento da linguagem e de repertório escultórico do barroco romano do século XVII para o universo das esculturas para Mafra, em Portugal do século XVIII e, daí, em direção à arte no Brasil do Setecentos". Assim sendo, a partir do estudo das figuras de anjos presentes nos entalhes do mobiliário brasileiro do século XVIII, ressalta esquemas iconográficos que sobrevivem ao tempo e que se ressignificam em diferentes contextos histórico-culturais.

Solange Lima, inspirada num artigo de Elizabeth Edwards, discute as práticas museológicas colecionistas, tomando como ponto de partida um armário (ou repositório) de doações feitas ao Museu Paulista, o A41, cujo conteúdo é composto primordialmente de fotografias de família produzidas em diferentes períodos e para diferentes circuitos das esferas pública e privada. A autora enfatiza, no artigo, as permanências nos enquadramentos e suportes materiais observáveis na produção dessas imagens do tipo "retrato" em diferentes momentos históricos e que se mantêm para além da diversidade de suas funções (afetivas, cívicas, religiosas, históricas e celebrativas). 
Além disso, Lima debruça-se sobre o processo ativo de musealização desses documentos iconográficos capazes, segundo ela, "de iluminar práticas cotidianas de uma sociedade calcada no regime escópico". Assim, ao partir de "um conjunto formado pela prática de coleta museológica", questiona em que medida esses objetos visuais podem ser considerados de interesse para tratar da visualidade da sociedade contemporânea e, ao mesmo tempo, pondera sobre os efeitos sociais provocados pelas políticas de coleta de acervos dos museus. Com tais questões a lhe guiar, e a partir de diferentes exemplos extraídos da sua prática profissional, a autora reflete sobre o tempo das imagens na vida cotidiana e como parte de acervos museológicos.

Já Artur Freitas, partindo da relação conflituosa entre a temporalidade das artes performáticas e a espacialidade dos museus de arte, analisa o caráter ritualístico da obra Situações Mínimas, realizada pelo artista plástico Artur Barrio em 1972. A análise é feita a partir do filme homônimo que documenta o ritual. A obra de Barrio é considerada, no texto, como "uma forma de profanação das condições institucionais inerentes a um museu de arte" e vista como um caso capaz de ajudar na compreensão dos embates entre vanguarda e museu, num contexto em que um Museu de Arte contemporânea (MAC) acabara de ser criado na cidade de Curitiba. Definindo o museu enquanto "frigorífico da história", o autor diz que o MAC, ainda que defensor de uma "museologia progressista", tinha que lidar com a precariedade financeira e com as contradições entre as regras especificamente expositivas de uma instituição museológica e o caráter anti-institucional da proposição "sacrílega" feita por Barrio, artista mais afinado aos "gestos insubordinados das vanguardas contraculturais" e que usa "da temporalidade e do próprio corpo enquanto dispositivos poéticos".

Como parte de um projeto mais amplo que investiga as representações cinematográficas da independência sob regimes autoritários na América Latina, o artigo de Ignácio Dell Valle Dávila privilegia a análise dos dois filmes históricos mais representativos da produção cinematográfica cubana dos anos 1960-70 (Lucia, de Humberto Solás, e La primera carga al machete, de Manuel Octavio Gómez), refletindo sobre os usos históricos do cinema enquanto parte de um projeto político de edificação da memória nacional. Por meio da análise fílmica, o autor observa como o Instituto Cubano de Arte e Indústria Cinematográfica (ICAIC) associou as guerras de independência com a revolução cubana, dentro de uma política cultural que privilegiava a produção de um cinema histórico que abordava o pro- 
cesso de independência como uma etapa no processo de luta pela liberdade nacional. Tais realizações cinematográficas estavam afinadas ao estabelecido pela lei de fundação do ICAIC, em 1959, segundo a qual a história cubana seria um dos principais temas do cinema da Ilha. $\mathrm{O}$ autor busca, ao mesmo tempo, avaliar as estratégias narrativas e estéticas que os dois cineastas desenvolveram em seus filmes e que lhes permitiram satisfazer as diretrizes dessa política cultural oficial sem renunciar às suas inquietudes criativas.

O artigo de Eduardo Morettin reflete sobre a participação do cinema na Exposition Coloniale Internationale et des Pays d'Outre-Mer, que ocorreu na cidade de Vincennes, vizinha a Paris, entre maio e novembro de 1931, pensando os usos históricos do cinema como projeto cívico articulado à ideia de nação. A exposição era dedicada a celebrar o império colonial constituído pela França desde o XIX. Dentro de uma perspectiva de valorização do Império Colonial, o autor afirma que o cinema teve papel decisivo na construção e no reforço de um imaginário voltado à afirmação da França como nação condutora da civilização e busca situar historicamente tanto a exposição quanto o cinema. Segundo ele, sabia-se que o potencial do cinema era equivalente ou até maior do que uma exposição universal, pois o cinema já era percebido como um dos principais vetores de intervenção no campo político.

Por fim, Rodrigo Tavares analisa os desenhos retratando o político paulista Ademar de Barros que foram publicados nos jornais comunistas Hoje e Novos Rumos. Seu intuito é compreender como as imagens foram utilizadas na construção da figura do político de acordo com os interesses do Partido Comunista Brasileiro (PCB), no período entre 1947 e 1964. O autor discute, dessa forma, os usos históricos da charge na mídia impressa, enquanto projeto de construção e de difamação de um mesmo personagem político, em momentos distintos da sua relação com o Partido Comunista.

Agradecemos aos colegas que colaboraram com o presente dossiê e possibilitaram ampliar os estudos e reflexões teóricas sobre a imagem e o tempo e o tempo na imagem no campo da história e áreas afins.

Maria Lúcia Bastos Kern

Rosane Kaminski

(Organizadoras) 